\title{
Particle size, compaction characteristic and tablet strength of spray-dried fermented jackfruit pulp - microcrystalline cellulose binary powder mixture
}

\author{
${ }^{1}$ Aznan, N.A., ${ }^{2}$ Koh, S.P., ${ }^{3}$ Ahmad Hamidi, F.W., ${ }^{1, *}$ Anuar, M.S. and ${ }^{4}$ Tahir, S.M. \\ ${ }^{1}$ Department of Process and Food Engineering, Faculty of Engineering, Universiti Putra Malaysia, 43400 \\ UPM Serdang, Selangor, Malaysia. \\ ${ }^{2}$ Biotechnology and Nanotechnology Research Centre, Malaysian Agricultural Research and Development \\ Institute (MARDI), PO Box 12301, General Post Office, 50774 Kuala Lumpur, Malaysia. \\ ${ }^{3}$ Bioengineering Technology Section, UniKL Malaysian Institute of Chemical and Bioengineering \\ Technology (UniKL MICET), 78000 Alor Gajah, Malacca, Malaysia \\ ${ }^{4}$ Department of Mechanical and Manufacturing Engineering, Faculty of Engineering, Universiti Putra \\ Malaysia, 43400 UPM Serdang, Selangor, Malaysia.
}

\section{Article history:}

Received: 10 April 2020

Received in revised form: 26

May 2020

Accepted: 10 July 2020

Available Online: 3 January

2021

Keywords:

Compaction,

Jackfruit,

Tablet,

Strength,

MCC,

Microcrystalline cellulose

\begin{abstract}
The tableting properties for fermented spray dried jackfruit (FJP) and microcrystalline cellulose (MCC) powders were studied. 25\% FJP $+75 \% \mathrm{MCC}, 50 \% \mathrm{FJP}+50 \% \mathrm{MCC}$ and $75 \%$ FJP $+25 \%$ MCC binary powder mixtures were compacted into tablet form at various compaction pressures ranging from 15.1 to $73.8 \mathrm{MPa}$. The properties were compared to pure FJP and MCC tablets. The addition of MCC resulted in a higher particle size and the increased in the plastic work of the tablet. The best ratio of FJP-MCC binary tablet was found to be at $25 \% \mathrm{FJP}+75 \% \mathrm{MCC}$ where the tablet showed the highest tensile strength. In conclusion, the addition of MCC to FJP improved the compaction characteristics and the tablet mechanical strength.
\end{abstract}

DOI:

https://doi.org/10.26656/fr.2017.5(S1).005

\section{Introduction}

Jackfruit (Artocarpus heterophyllus Lam) is a nonseasonal fruit commonly found in Asia (Ranasinghe et al., 2019). It is one of the main fruits produced in Malaysia whereby the jackfruit plantation covers approximately 4895.03 ha with a production of $31,022.89 \mathrm{Mt}$ as in a recent statistics published by the Department of Agriculture Malaysia (2018). One of the popular variety of jackfruit amongst the consumers in Malaysia is 'Tekam yellow' variety. The fruit has an oblong shape, showing yellowish green colour when it is ripe, with the average fruit weight of between $16-20 \mathrm{~kg}$ (Ismail and Kaur, 2013). 'Tekam Yellow' has a less juicy texture and tasted sweeter than the Mantin and Mastura varieties (Ismail and Kaur, 2013). In addition, jackfruit in the form of fresh cuts was also found to be favoured by the consumer (Burfield, 2017). However, degradation in the quality of jackfruit fresh cuts under storage would be detrimental to its nutritional qualities (Saxena et al., 2009; Ramli et al., 2017). One of the options for the use of jackfruit pulp was to further dry it and forming it into powder before storing it inside a suitable packaging to prolong its shelf life (Pua et al., 2008). A previous study also showed the potential of fermented jackfruit pulp containing relatively higher total phenolics content and antioxidant activities (Aziz et al., 2017). In this previous study, the jackfruit pulp was fermented by either adding yeast or acetic acid bacteria for seven days at $30^{\circ} \mathrm{C}$. However, the use of powder and liquid materials would normally take up more spaces during storage. For easy and accurate consumption, compacted powder or a tablet is more preferably than in powder or liquid form. In tablet processing, the importance of tablet strength and its compaction characteristics are vital for successful tabletting operation (Pitt and Sinka, 2007; Mohan, 2012). In most cases, the active ingredient of which to be made into tablet has poor compaction characteristics. Hence, the active ingredient would then be added with various types of excipients to improve the active ingredient compaction characteristics. This has been extensively studied by previous researchers using various 
pharmaceutical tablet excipients such as mannitol and microcrystalline cellulose (Jacob et al., 2007). Even within the same category such as lactose and mannitolbased excipients, different grades produced by a certain manufacturer will have different compaction characteristics (Paul et al., 2018). Although the compaction characteristics of common excipients have been well documented in the literature, experiments must be conducted to examine their behaviour after being added with the active ingredient. Meanwhile, the particle size of the powder also influences the processing conditions, such as smaller particles adhesion to the die and punch thus can cause problems during the tabletting process (Rajani et al., 2018). Therefore, particle size is an important parameter that must be evaluated for the material to be compacted and is a common parameter included in the material data sheet for powder materials.

The main objective of this current work is to produce fermented spray-dried jackfruit pulp tablet with the addition of a common pharmaceutical excipient, microcrystalline cellulose. The particle size of the binary powder mixture will be determined. The compaction characteristics derived from the force-displacement data obtained during the compaction process and the strength of the formulated tablet will also be evaluated. These valuable data will be useful for product formulators with the intention of formulating tablets using microcrystalline cellulose-based excipients mixture with derived jackfruit powder from spray drying processes.

\section{Materials and methods}

\subsection{Raw materials}

Microcrystalline cellulose used was of pharmaceutical grade (Avicel PH102, DuPont, US). The fermented jackfruit pulp beverage was obtained from MARDI. The fermented jackfruit pulp beverage was produced using a symbiotic culture of bacteria and yeast under controlled fermentation process, which is a propriety process of the Malaysia Agricultural Research and Development Institute (MARDI). The fermented jackfruit pulp powder was formed through spray drying (Spray Dryer model B-290, Buchi, Malaysia) of this fermented jackfruit pulp beverage containing $8 \% \mathrm{w} / \mathrm{w}$ maltodextrin (DE10) and $2 \% \mathrm{w} / \mathrm{w}$ arabic gum using an inlet air temperature of $170^{\circ} \mathrm{C}$ and airflow rate of 35 $\mathrm{m}^{3} \mathrm{hr}^{-1}$. The spray drying conditions were obtained from preliminary unpublished work to convert the fermented jackfruit pulp beverage into powder form.

\subsection{Particle size}

The important powder properties determined in this work was the particle size of the powder raw materials used. The particle size was determined using a particle size analyser (Malvern Mastersizer 2000, Malvern, UK) in terms of the particle median size, $\mathrm{d}_{50}$ (Shamjuddin et al., 2014).

\subsection{Sample preparation and tablet formation}

The fermented jackfruit pulp spray-dried powder (FJP) was mixed with microcrystalline cellulose powder (MCC) using a dry powder rotator (Glas-Col, USA) producing FJP mixtures containing 100\% w/w FJP, 25\% $\mathrm{w} / \mathrm{w} \mathrm{MCC}+75 \% \mathrm{w} / \mathrm{w}$ FJP, $50 \% \mathrm{w} / \mathrm{w} \mathrm{MCC}+50 \% \mathrm{w} / \mathrm{w}$ FJP, $75 \% \mathrm{w} / \mathrm{w}$ MCC $+25 \% \mathrm{w} / \mathrm{w}$ FJP and $100 \% \mathrm{w} / \mathrm{w}$ MCC. These compositions were chosen to reflect the increase in the amount of MCC added to the FJP formulation through a $25 \% \mathrm{w} / \mathrm{w}$ incremental increase between each subsequent formulation. These composition values were also used in previous work involving the mixing of various pharmaceutical excipients conducted by Al-Ibraheemi et al. (2013). $1 \mathrm{~g}$ tablets were produced inside $13-\mathrm{mm}$ stainless steel die set (Specac, UK) formed at compaction pressures of 15.1 $\mathrm{MPa}, 30.1 \mathrm{MPa}, 45.2 \mathrm{MPa}$ and $73.8 \mathrm{MPa}$ using a universal testing machine (model 5566, Instron, USA). Other compaction conditions were similar to previous work by Jamar et al. (2020).

\subsection{Compaction characteristic}

The force-displacement data recorded during the compaction process was utilized to evaluate the plastic work done during the compaction process. The plastic work is the area under the force-displacement curve obtained in the loading stage of the compaction process (Mohammed et al., 2005; Shamsudin et al., 2012; Shamsudin et al., 2014). It is a common parameter used in representing the plastic deformation incurred by the particle bed inside the die cavity during tablet formation (Radzali et al., 2018). Relatively higher plastic work signify higher plastic deformation leading generally to mechanically stronger tablet (Shamsudin et al., 2012; Radzali et al., 2018).

\subsection{Tablet mechanical strength measurement}

The tablet mechanical strength was evaluated using the indirect tensile strength test or also known as the Brazilian test (Fell and Newton, 1970; Yaakub et al., 2018; Radzali et al., 2018). The tablet was placed a flat horizontal rigid surface and compressed on its major cylindrical axis using the universal testing machine (Model 5566, Instron Canton MA, U.S.A.). The tensile strength of the tablet was then calculated using:

$$
\sigma_{X}=\frac{2 P}{\pi D H}
$$

where $\sigma_{X}$ is the tensile strength of the tablet, $P$ is the fracture load, $D$ is the diameter of the tablet and $H$ is the 
thickness of the tablet.

\section{Results and discussion}

Table 1 shows the particle median sizes of the raw materials used in this work. ANOVA with Tukey statistical analysis was conducted for the data in Table 1. It was found that the microcrystalline cellulose (MCC) particles were significantly larger $(\mathrm{P}<0.05)$ than the spray-dried fermented jackfruit pulp (FJP) particles, about 5.6 times larger in terms of their median size, $d_{50}$. It could also be observed in Table 1 that as the MCC composition increased in the binary mixture of FJPMCC, the resulting median particle size of the mixture increased. As one would expect a linear increase in the particle median size as the larger-sized MCC particles were added, this was not seen as portrayed by the results in Table 1 . When the binary mixture consisting of $25 \%$ $\mathrm{w} / \mathrm{w} \mathrm{MCC}+75 \% \mathrm{w} / \mathrm{w}$ FJP, there were no significant differences $(\mathrm{P}<0.05)$ between the particle median sizes of this mixture with the pure $100 \%$ w/w FJP powder. However, with the further addition of $\mathrm{MCC}$ to $50 \% \mathrm{w} / \mathrm{w}$ $\mathrm{MCC}+50 \%$ FJP, the resulting binary powder mixture particle median size significantly $(\mathrm{P}<0.05)$ displayed an exponential increase of about 3.2 times compared to the case when just $25 \% \mathrm{w} / \mathrm{w}$ MCC was added to the formulation. When the mass percentage of MCC was higher than those of FJP as for the case when the binary mixture contained $75 \% \mathrm{w} / \mathrm{w} \mathrm{MCC}+25 \% \mathrm{w} / \mathrm{w}$ FJP, the relative increase in the particle median size was insignificantly $(\mathrm{P}>0.05)$ lower at about 1.2 times compared when the equal mass of MCC and FJP were present in the binary powder mixture.

Table 1. The particle median size of the raw materials

\begin{tabular}{cc}
\hline Powder composition $(\% \mathrm{w} / \mathrm{w})$ & Particle median size, $\mathrm{d}_{50}(\mu \mathrm{m})$ \\
\hline $100 \%$ FJP & $24.67 \pm 15.74$ \\
$25 \% \mathrm{MCC}+75 \%$ FJP & $27.85 \pm 4.45$ \\
$50 \% \mathrm{MCC}+50 \%$ FJP & $89.05 \pm 11.60$ \\
$75 \% \mathrm{MCC}+25 \%$ FJP & $109.74 \pm 1.70$ \\
$100 \% \mathrm{MCC}$ & $138.75 \pm 44.08$ \\
\hline
\end{tabular}

Generally, when higher compaction pressures were used to form the tablets, relatively higher values of the plastic works were obtained for all the different tablet compositions as illustrated in Figure 1 The trend of increasing plastic work with the increase in the compaction pressure was well documented in the literature such as for the case of coffee tablets (Jamar et al., 2020), urea fertilizer tablets (Shamsudin et al., 2014; Shamsudin et al., 2019), carboxymethyl cellulose tablets (Radzali et al., 2018), lactose tablets (Yaakub et al., 2018), sweet potato and stevia tablets (Shamsudin et al., 2012). This indicated the relatively higher plastic deformation of the particles at higher compaction pressures used during tablet formation. The plastic work values were determined during the compaction process when the tablets were still confined within the die cavity. Therefore, it could not be viewed as the total permanent plastic deformation of the particles incurred during the loading stage of the compaction process. The physical expansion of the tablet body or tablet relaxation could occur during the subsequent unloading and ejection stages of the compaction process as well as during tablet storage (Hwang et al., 2001; Anuar and Briscoe, 2009; Shamjuddin et al., 2014).

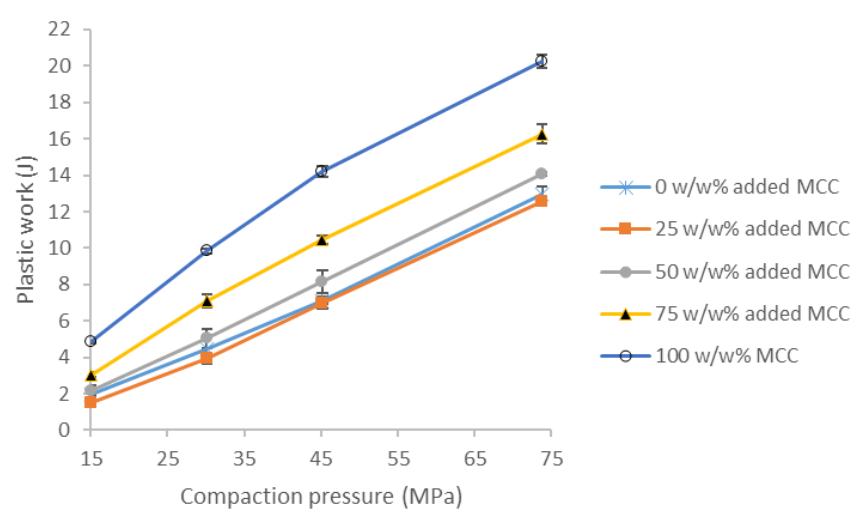

Figure 1. The plastic work values at various compaction pressures and compositions

In terms of the composition effects on plastic work, several key trends could be observed in Figure 1. The plastic works for the different composition of MCC+FJP have closer values at the lowest compaction pressure of 15.1 MPa. As the compaction pressure increased, the plastic work values for the tablets containing $50 \% \mathrm{w} / \mathrm{w}$ and more of MCC started to differ more from each other. Meanwhile, when only $25 \% \mathrm{w} / \mathrm{w}$ MCC was present, the plastic work was not clearly different from the plastic work of the tablet containing $100 \% \mathrm{w} / \mathrm{w}$ FJP even though the compaction pressure increased. This observed scenario was similar to those discussed previously for the case of the particle median size of the binary powder mixture of MCC + FJP, where no significant difference was observed in the particle median size compared to $100 \% \mathrm{w} / \mathrm{w}$ FJP when only $25 \% \mathrm{w} / \mathrm{w}$ MCC was present in the mixture. This shows on a first-order basis that the particle median size of the mixture affected the resulting compaction characteristics of the mixture in terms of the plastic work values.

Another important finding was that the addition of MCC increased the plastic work of the tablets, where the highest plastic work was obtained for $100 \% \mathrm{w} / \mathrm{w}$ MCC tablets. Pure FJP tablets and those containing $25 \% \mathrm{w} / \mathrm{w}$ MCC displayed low values of the plastic work, indicating relatively lower particle plastic deformation during the loading stage of the compaction process. This also showed that the MCC particles exhibited relatively higher plastic deformation compared to FJP particles, where the addition of MCC particles increased the plastic 
work of the tablets hence the overall binary mixture particle plastic deformation. This was also found for the case of the binary mixture of MCC-lactose and MCCsodium starch glycolate powders (Al-Ibraheemi et al., 2013).

In tandem with the increase in plastic work, the tablet tensile strength also increased with increasing compaction pressure as illustrated in Figure 2. The increase in the tablet strength when higher compactions pressures were used during tablet formation was also observed for the compaction of pure MCC tablets (Shamsudin et al., 2011; Radzali et al., 2018). This was due to the relatively higher particle plastic deformation allowing more inter-particulate bond formation. The higher inter-particulate bond formation would then enhanced the mechanical integrity of the tablet as depicted by the higher tablet tensile strength. Meanwhile, the tablet tensile strength values for the various compositions were nearly similar at the lowest compaction pressure of $15.1 \mathrm{MPa}$, in accordance with the trend observed with the plastic work values at this lowest compaction pressure. Furthermore, a similar trend with those seen for the particle median size and plastic work was observed for the case when only $25 \% \mathrm{w} / \mathrm{w}$ of MCC was present in the tablet, the tablet tensile strength was nearly similar to the pure $100 \% \mathrm{w} / \mathrm{w}$ FJP tablets. Further addition of $\mathrm{MCC}$ so that there were equal amounts of MCC and FJP in the formulation resulted in the increase of the overall tablet tensile strength. The maximum amount of $75 \% \mathrm{w} / \mathrm{w} \mathrm{MCC}$ in the tablet resulted in the highest tablet tensile strength values obtained in this work. However, interestingly, the tablets made from $100 \% \mathrm{w} / \mathrm{w}$ of MCC have lower tablet tensile strength values in comparison with the tablets containing $50 \% \mathrm{w} /$ $\mathrm{w}$ and $75 \% \mathrm{w} / \mathrm{w}$ MCC. Therefore, the FJP-MCC tablet formulations in this work followed the Type I (c) (Sun, 2016) classification of the binary tablet tensile strength variations with the composition at the higher compaction pressure range used in this study. This is for the case whereby in some compositions of the binary mixture, the resulting tablet tensile strength values exceeded both the pure constituent tablet tensile strength values (Sun, 2016). It was also important to note that although the plastic work values for the $50 \% \mathrm{w} / \mathrm{w}$ and $75 \% \mathrm{w} / \mathrm{w} \mathrm{MCC}$ tablets were relatively lower than those for $100 \% \mathrm{w} / \mathrm{w}$ MCC tablets as seen in Figure 2 but the latter exhibited lower tablet tensile strength values. Hence, higher plastic works did not always produce relatively stronger tablets as found in this current study for the case of FJP-MCC tablets, which was also found by previous work using carboxymethylcellulose (CMC) (Radzali et al., 2018).

However, the homogeneity of the distribution of the FJP-MCC particles within the tablet itself was not performed. Previous work conducted by Eiliazadeh et al. (2003) dealt with the internal density distribution within a tablet structure. Even though the internal tablet homogeneity was not studied, based upon the standard deviations obtained for the responses in Table 1, Figure 1 and Figure 2 respectively, the deviations for each data points were generally low. Therefore, it could be assumed that the internal tablet homogeneity for each tablet formed was consistently similar hence no significant effects of the internal particle distribution on the measured tablet properties conducted in this work.

\section{Conclusion}

In conclusion, spray-dried fermented jackfruit pulp powder (FJP) was successfully made into tablet form. The addition of microcrystalline cellulose (MCC) enhanced the particle median size, compaction characteristic (plastic work) as well as the tablet tensile strength. The increase in the compaction pressure positively affected plastic work and tablet strength. The increase in the MCC content positively increased plastic work. However, for the case of the tablet tensile strength, the increased in the MCC content increased the tablet tensile strength higher than for pure FJP tablet and higher than pure MCC tablet at higher MCC contents in the MCC+FJP tablet. The best formulation of FJP-MCC binary tablet was obtained at 25\% FJP $+75 \%$ MCC composition, where the formulated tablet exhibited the highest tensile strength. The addition of MCC to FJP

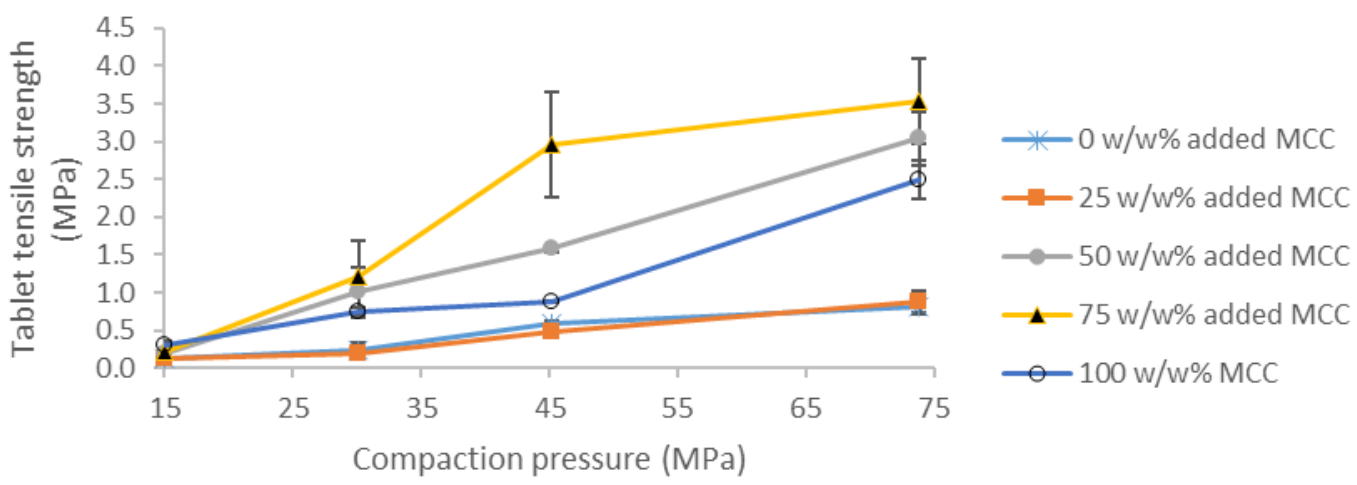

Figure 2. The tablet tensile strength at various compaction pressures and compositions 
improved the compaction characteristics and the tablet mechanical strength, therefore achieving the objective of this work. This study can help formulators to produce a mechanically viable fermented jackfruit pulp tablet.

\section{Acknowledgement}

The authors gratefully acknowledging the funding received from Universiti Putra Malaysia IPS grant vote no: 9660700 .

\section{References}

Al-Ibraheemi, Z.A.M., Anuar, M.S., Taip, F.S., Amin, M.C.I. and Tahir, S.M. (2013). Deformation and mechanical characteristics of compacted binary mixtures of plastic (microcrystalline cellulose), elastic (sodium starch glycolate), and brittle (lactose monohydrate) pharmaceutical excipients. Particulate Science and Technology: An International Journal, 31(6), 561-567. https:// doi.org/10.1080/02726351.2013.785451

Anuar, M.S. and Briscoe, B.J. (2009). The elastic relaxation of starch tablets during ejection. Powder Technology, 195(2), 96-104. https://doi.org/10.1016/ j.powtec.2009.05.019

Aziz, N., Koh, P.S., Mustaffa, R., Abdullah, R. and Hamid, N.S.A. (2017). Effect of yeast and acetic fermentation on phytochemical and antioxidant properties of jackfruit pulp (Artocarpus heterophyllus L.). Educatum Journal of Science, Mathematics and Technology, 4(1), 15-23.

Burfield, T. (2017). Jackfruit, big and on the rise. Retrieved on September 6, 2019 from Produce Retailer website: https:/www.produceretailer.com/ article/news-article/jackfruit-big-and-rise

Department of Agriculture Malaysia (2018). Fruit crop statistics. Putrajaya: Department of Agriculture Malaysia.

Eiliazadeh, B., Brisoce, B.J., Sheng, Y. and Pitt, K.G. (2003). Investigating density distributions for tablets of different geometry during the compaction of pharmaceuticals. Particulate Science and Technology, 21(4), 303-316. https:// doi.org/10.1080/716100572

Fell, J.T. and Newton, J.M. (1970). Determination of tablet strength by diametral compression test. Journal of Pharmaceutical Sciences, 59(5), 688-691. https://doi.org/10.1002/jps.2600590523

Ismail, N. and Kaur, B. (2013). Consumer preference for jackfruit varieties in Malaysia. Journal of Agribusiness Marketing, 6, 37-51.

Jacob, S., Shirwaikar, A.A., Joseph, A. and Srinivasan
K.K. (2007). Novel co-processed excipients of mannitol and microcrystalline cellulose for preparing fast dissolving tablets of glipizide. Indian Journal of Pharmaceutical Sciences, 69(5), 633-639. https:// doi.org/10.4103/0250-474X.38467

Jamar, A., Anuar, M.S. and Tahir, S.M. (2019). Frictional effects, mechanical strength, and disintegration of coffee mix tablet, effervescent coffee mix tablet and with added lubricant. Particulate Science and Technology, 2019, 1666950. https://doi.org/10.1080/02726351.2019.1666950

Mohammed, H., Briscoe, B.J. and Pitt, K.G. (2005). The interrelationship between the compaction behaviour and the mechanical strength of pure pharmaceutical tablets. Chemical Engineering Science, 60(14), 3941 -3947. https://doi.org/10.1016/j.ces.2005.02.027

Mohan, S. (2012). Compression physics of pharmaceutical powders: a review. International Journal of Pharmaceutical Sciences, 3(6), 15801592.

Paul, S., Chang, S.Y., Dun, J., Sun, W.J., Wang, K., Tajarobi, P., Boissier, C. and Sun, C.C. (2018). Comparative analyses of flow and compaction properties of diverse mannitol and lactose grades. International Journal of Pharmaceutics, 546(1-2), 39-49. https://doi.org/10.1016/j.ijpharm.2018.04.058

Pitt, K. and Sinka C. (2007). Tabletting. In Salman, A.D., Hounslow, M.J. and Seville, J.P.K. (Eds.). Handbook of Powder Technology Volume 11: Granulation. USA: Elsevier.

Pua, C.K., Hamid, N.S.A., Tan, C.P., Mirhosseini, H., Rahman, R.A. and Rusul, G. (2008). Storage stability of jackfruit (Artocarpus heterophyllus) powder packaged in aluminium laminated polyethylene and metallized co-extruded biaxially orientated polypropylene during storage. Journal of Food Engineering, 89(4), 419-428. https:// doi.org/10.1016/j.jfoodeng.2008.05.023

Radzali, N.S., Jaafar, N.M., Anuar, M.S. and Tahir, S.M. (2018) Compaction, mechanical strength and disintegration of palm oil empty fruit bunch (EFB) carboxymethyl cellulose (CMC) tablets. Food Research, 2(6), 520-525. https://doi.org/10.26656/ fr.2017.2(6).131

Rajani, C., Kumar, D.D., Jaya, D. and Kumar, J.A. (2018). Effects of granule particle size and lubricant concentration on tablet hardness containing large concentration of polymers. Brazilian Journal of Pharmaceutical Sciences, 53(3), 1-8. https:// doi.org/10.1590/s2175-97902017000300149

Ramli, R.A., Azmi, A, Johari, N.R. and Noor, S.M. (2017). Minimally processed jackfruit: opportunity 
for the foodservice industry. Journal of Food Research, 6(1), 1-6. https://doi.org/10.5539/ jfr.v6n1p1

Ranasinghe, R.A.S.N., Maduwanthi, S.D.T. and Marapana, R.A.U.J. (2019). Nutritional and health benefits of Jackfruit (Artocarpus heterophyllus Lam.): a review. International Journal of Food Science, 2019, $4327183 . \quad \mathrm{https} / /$ doi.org/10.1155/2019/4327183

Saxena, A., Bawa, A.S. and Paju, P.S. (2009). Phytochemical changes in fresh-cut (Artocarpus heterophyllus L.) bulbs during modified atmosphere storage. Food Chemistry, 115(4), 1443-1449. https:// doi.org/10.1016/j.foodchem.2009.01.080

Shamjuddin, A., Anuar, M.S. and Tahir, S.M. (2014). Characteristics of tableted Roselle (Hibiscus sabdariffa Linn.) wit addition of sodium starch glycolate. Particulate Science and Technology: An International Journal, 32(4), 384-391. https:// doi.org/10.1080/02726351.2014.880095

Shamsudin, I.S., Anuar, M.S. and Tahir, S.M. (2012). Compaction of sweet potato (Ipomoea Batatas L.) and stevia rebaudiana food powders. Particulate Science and Technology: An International Journal, 30(2), 135-144. https:// doi.org/10.1080/02726351.2011.552098

Shamsudin, I.S., Anuar, M.S., Yusof, Y.A., Mohd. Hanif, A.H. and Tahir, S.M. (2014). Effect of particle size on direct compaction of urea fertilizer. Particulate Science and Technology: An International Journal, 32(6), 544-553. https:// doi.org/10.1080/02726351.2014.930942

Shamsudin, I.S., Anuar, M.S., Yusof, Y.A., Mohd. Hanif, A.H. and Tahir, S.M. (2019). Improvement in the mechanical strength of compacted urea fertilizer tablets through die wall lubrication. Pertanika Journal of Science and Technology, 27(1), 193-203.

Sun, C.C. (2016). A classification system for tableting behaviors of binary powder mixtures. Asian Journal of Pharmaceutical Sciences, 11(4), 486-491. https:// doi.org/10.1016/j.ajps.2015.11.122

Yaakub, N.A., Anuar, M.S. and Tahir, S.M. (2018). Compaction behaviour and mechanical strength of lactose-sodium starch glycolate and lactosecroscarmellose sodium binary tablets. IOP Conference Series: Materials Science and Engineering, 342, $012026 . \quad \mathrm{https} / / /$ doi.org/10.1088/1757-899X/342/1/012026 